\title{
International Congress of Anthropological and Ethnological Sciences
}

$\mathrm{T}$ HE first session of the recently constituted International Congress of Anthropological and Ethnological Sciences was held under the patronage of H.R.H. the Duke of York and the presidency of the Earl of Onslow at University College, London, on July 30-August 4. Owing to the regretted absence of the Duke of York through illness, the Congress was declared open on July 30 by H.R.H. Prince George.

The members of the Congress numbered more than eleven hundred, of whom about a thousand were present, including delegates from forty-two foreign countries and British dependencies, and representatives of a large number of universities, academies and other learned bodies.

The work of the Congress was distributed among eleven sections and more than four hundred communications were presented. The sectional presidents were : $A a$ (Anatomy and Physical Anthropology) Sir Grafton Elliot Smith (London); $A b$ (Anthropometry) Prof. H. J. Fleure (Manchester); $B$ (Psychology) Prof. F. C. Bartlett (Cambridge); $C$ (Demography) Prof. C. B. Faweett (London); Da (Ethnography, general) Dr. A. C. Haddon (Cambridge); $D b$ (Ethnography of Africa) Rev. E. W. Smith (London); Dc (Ethnography of America) T. A. Joyce (London); $E$ (Technology) H. Balfour (Oxford); $F$ (Sociology) Prof. C. G. Seligman (London); $G$ (Religions) Prof. E. O. James (Leeds); $H$ (Linguistics and Writing) Dr. Alan H. Gardiner (London).

In addition to the communications presented in the sections, addresses to the Congress as a whole were delivered by Prof. T. C. Hodson on "Certain Aspects of the Indian Census, 1931", on August 1 ; Dr. R. R. Marett on "Movements and Tendencies in the Anthropological and Ethnological Sciences", on August 2 ; and by Prof. J. B. S. Haldane on "Anthropology and Human Biology", on August 3. In addition, the Royal Anthropological Institute met with the Congress for the delivery of the Huxley Memorial Lecture by Sir Aurel Stein on "The Prehistory of the Indo-Iranian Borderlands as illustrated by Recent Exploration", on July 31 .

Any attempt to give even a list of the communications within a reasonable limit of space is an impossibility, nor can attention be directed to all the papers which dealt with topics of outstanding interest. The selection of questions to which discussion was directed in the preliminary outline of the programme issued with invitations to the Congress had been drawn up with much care to cover all the more important topics of discussion among anthropologists at the present moment, including matters of practical significance, such as the position of witchcraft in Africa under present administrative regulation. Attention will be confined here to a few of the questions discussed, without any implication as to their importance or interest in relation to others which must be passed over owing to limitations of space.

The opening remarks of the president of the Section of Anatomy, Sir Grafton Elliot Smith, when directing attention to the bearing of the study of race and culture on the claims now being put forward on behalf of the Aryans in the political life of Germany, and pointing out that the only contribution the Aryans could have made to the culture of early Mesopotamia was to borrow from it, struck a note which was characteristic throughout the proceedings of all the sections. This was the realisation that the study of man deals with a living subject of vital import to man. It was apparent not merely in questions of direct practical applications, such as the problems of dysharmonic cultural contact and administration in tropical and sub-tropical dependencies, but also in other matters, such as descent and race, more often treated as though they were solely of scientific interest.

Two discussions in the Section of Anatomy were especially interesting in view of current controversy and discussion of method, one on "Man's Relation to the Primates", the other on the "Anthropological Aspect of Blood Grouping". The former was opened by Prof. W. E. Le Gros Clarke (Oxford), who argued that the human stem might already have become segregated at a much earlier stage in evolution than was generally supposed. It had been held that this took place in miocene times in a Dryopithecus group, which also provided the direct ancestors of the modern ape; but recent discovery had established that the modern apes were fully differentiated by the beginning of the miocene. Prof. W. K. Gregory (New York) carried further his deductions from detailed comparison of the extremities of man and the apes, and Dr. L. S. B. Leakey (Cambridge) demonstrated the features, more particularly the characters of the teeth, upon which he had based his classification of Homo kanamensis, directly ancestral to modern man. The results of an examination of the palæontological evidence associated directly with early types of man with the view of determining the relative date of these types, by Mr. A. T. Hopwood (London), not only pointed to Eoanthropus as the earliest form, but also, in showing a closer affiliation of the human form with the western group of fossil anthropoids, lent support to the view that the place of origin of man might be expected to be nearer the west than the east. The president, in closing this session, said that the discussion, like others on this subject, had tended to consider man's place in time rather than his relation to the primates. While pointing to the high antiquity now attributed to modern man on the evidence of Dr. Leakey's discoveries in East Africa, as well as of the Lloyd's skull, he expressed some doubt as to the wisdom of basing a separate classification of Homo kanamensis on a pathological specimen.

In the discussion on blood-grouping, Prof. V. Suk (Brno) gave a comprehensive summary of work on this method of investigation of racial questions and more especially of recent developments. Hestressed, though not unduly, the difficulty, as yet, of arriving at any clear-eut conclusion, and held that the new facts, in so far as they can be called fully established facts, cannot yet be completely correlated with other traits to represent a criterion in racial classification. Dr. H. J. T. Bylmer (Bloemendaal, Netherlands), on the other hand, in the light of his experience in the Dutch East Indies, endeavoured to find a resolution of such difficulties; while Prof. Ruggles Gates (London) offered a genetical interpretation of the blood group with special reference to the problem of the American Indian. This pointed to isolated tribes from East Asiatic islands as the ancestors of the Amerindian post-glacial migrants. He referred also to the evidence from other peoples of peripheral distribution, and concluded that the blood-groups did 
furnish important evidence of racial relationships, migrations and mixtures. They were also useful in confirming conclusions regarding crossing reached on the grounds of physiognomy. In Section $A b$ (Anthropometry) a great part of the time available was devoted to the discussion of the system of measurement in anthropometry and its technique. Important progress was made. Further attention will be given to this subject later.

In Section $B$ (Psychology), a communication by Dr. C. S. Myers (London) was of special interest in its bearing on the current topic of mental characters and race. He pointed out th it while primitive man of to-day, it had been found, was not radically different from his more advanced brother, most of such differences as were observed were material for the social psychologist, for they were mainly due to the social factors of environment and tradition; nevertheless, the possible inheritance of "collective unconscious' factors could not be wholly ruled out.

In the same section, Prof. Arnold J. Toynbee (London), on "Psychological Problems which arise from the Contact of Cultures", said that the historians of the future would say that the great event of the twentieth century was the impact of Western civilisation upon all other living societies of the world of that day. The principle of national self-government had arisen in a West-European social environment, which was exceptional ; but the Near Eastern peoples had been led by West-European d minance to 'scrap' their own institutions, and havoc had ensued.

In the final session of the Congress, a number of important resolutions were passed and research committees appointed. It was decided that the next meeting of the Congress should take place in 1938 in Copenhagen, the president to be Prof. T. Thomsen of Copenhagen.

\section{Lightning and High-Voltage Power Transmission Lines}

$I^{N}$ a paper read to the South African Institute of Electrical Engineers in November last by E. F. Rendell and H. D. Gaff, an analysis is given of the faults due to lightning on the overhead lines connecting two stations-the Witbank and the Brakpan -belonging to the Victoria Falls and Transvaal Power Co. of South Africa. There are two parallel three-phase circuits connecting the two stations and the maximum load is 350 kilowatts. The voltage between phases is the same as that of the British Grid, namely, $132 \mathrm{kv}$. The three lines forming each set are of steel-cored aluminium and are in a vertical plane, the distance between the two planes being 23 feet. There is no transposition of the conductors (sometimes done to avoid interference with neighbouring telephones) and so they are parallel to one another. The distance between the top conductor of a set and the middle conductor is $12 \mathrm{ft}$., being the same as the distance between the middle and the lower conductor. An earthed guard wire was originally placed above the two sets at a distance of $18 \mathrm{ft}$. from the top wire of each set. The height of the lowest conductors from the earth averages $56 \mathrm{ft}$. The function of the guard wire is to 'protect' the circuits from lightning. There are 303 suspension towers for the circuits between the two stations.

Two cinematograph cameras were installed at Witbank, and one at Brakpan, three years ago. Any full voltage fault automatically starts the cameras recording. In this way, very complete film records have been obtained of the currents, voltages, etc., during every fault for the last three years. It is generally agreed that there are four possible ways in which a lightning fault may be caused on a power line. It may be due to the induced voltage in the conductors causing a rise of pressure which flashes over the string of insulators to the earth. Or it may bs due to the lightning flash striking a suspension towər directly. It might strike a conductor directly. There is a possibility also that a streamer from a lightning flash to the earth might strike a conductor. The records provide some evidence that the first two causes are quite possible, but they only give negative results with regard to the last two.

It is well known that lightning faults are rarely evenly distributed along the length of a transmission line. In general, some sections of the line are immune from faults whilst in other sections, severe and continually recurring faults may be experienced. The reasons usually given are varying radioactivity on the geological strata causing more frequent flashes in certain locations. Variations in the electrical resistivity of the geological strata, which have the effect of altering the resistance to the earth of the various towers, may have an effect on the frequency of the occurrence of the faults. The records show that no faults occurred between towers 264-297, a distance of about six miles, and there were 65 between towers $120-164$, a distance of roughly eight miles. Owing to faults recurring in a particular section, additional guard wires were erected over it. This, however, seems to have had the effect of increasing the number of faults.

The authors have found that there are appreciable differences in what happens when a fault on a single line occurs and when there is a simultaneous fault on two lines. The differences occurred so consistently that they indicate a fundamental difference in the active cause in the two cases. When a fault occurs on one of the circuits only, it is rare for more than one phase to be affected. With double-line faults, the majority occur on only one phase, but there are an appreciable number affecting two phases. Invariably the same phase or phases of both lines are affected. With single-line faults, the top conductor is the one most frequently affected; with double-line faults all phases are approximately equally affected. The equal distribution of faults between all phases in the case of double-line faults suggests that such a fault is due to a direct stroke on the tower causing an over-voltage, and consequently the highest conductors at the instant of the stroke are the ones affected.

The value of the resistance to earth of a tower seems to have little effect on the number of singleline faults that occur. With double-line faults, on the other hand, increasing the insulation diminishes their number without increasing the number of faults on neighbouring towers. The records show quite definitely that with single-line faults the conductor furthest removed from the earth is the one most frequently struck, whilst with double-line faults the conductors are all equally liable to be struck. They also show that with single-line faults additional 